\title{
Catheterization of the pulmonary artery in transposition of the great arteries using a Swan-Ganz flow-directed catheter
}

\author{
Suzanne M. Jones and G. A. H. Miller \\ From the Cardiac Department, Brompton Hospital, London
}

The Swan-Ganz flow-directed balloon-tipped catheter provides a rapid, simple, and safe method of catheterizing the pulmonary artery in neonates and children with complete transposition of the great arteries. With a minor modification of the catheter, the success rate in such patients has been Ioo per cent.

Catheterization of the pulmonary artery in cases of complete transposition of the great arteries is an important part of the study of such patients and essential for their preoperative evaluation. It permits calculation of pulmonary flow and resistance, the detection of pulmonary valve or subvalve stenosis, and the assessment of the adequacy of palliative pulmonary artery banding. Unfortunately catheterization of the pulmonary artery in such cases may be difficult or impossible - particularly when the ventricular septum is intact. In their original report of the use of a flow-directed balloon-tipped catheter, Swan and associates (1970) anticipated that their catheter might prove useful in the study of infants and children with complex cardiac malformations. We report here the use of the Swan-Ganz catheter for catheterization of the pulmonary artery in 35 cases of transposition, with results which, in our opinion, amply justify the optimistic forecast of Swan and associates.

\section{Methods}

A No. 5 French double-lumen Swan-Ganz flow-directed catheter was used in all cases. The catheter was introduced via a cut-down on the right saphenous or femoral vein and advanced via a patent foramen ovale or atrial septal defect to the left atrium under fluoroscope control. The balloon was then inflated using carbon dioxide to avoid the danger of air embolism should accidental balloon rupture occur. Inflation of the balloon resulted in advancement of the catheter to left ventricle and pulmonary artery (Fig. I). Early in our experience there was a tendency for the catheter to advance to the apex of the left ventricle rather than to the pulmonary artery. This

Received I8 August 1972. was overcome by moulding a $180^{\circ}$ curve on the distal 2 $\mathrm{cm}$ of the catheter using boiling water to soften the catheter before moulding. Once the catheter had entered the pulmonary artery the balloon was deflated and pressure recorded and samples taken in the usual way.

\section{Results}

\section{Complete (dextro-) transposition}

There were 23 patients, aged 2 days to ro years (Fig. 2). The pulmonary artery was entered in 18 of the 23 patients $(78 \%)$. The average time from introduction of the catheter to the recording of pulmonary artery pressure (or from entry to LA to recording of pulmonary artery pressure in cases where the Swan-Ganz catheter was first used for catheterization of the right side of the heart) was 4.4 minutes in only 4 cases was the time recorded as in excess of 5 minutes. In one case the time taken was not recorded. There was no relation between the age of the patient and failure to enter the pulmonary artery (Fig. 2). The presence of pulmonary stenosis did not appear to be a bar to successful catheterization of the pulmonary artery: of the 18 patients in whom the pulmonary artery was entered, 9 had pulmonary valve gradients ranging between Io $\mathrm{mmHg}$ and $220 \mathrm{mmHg}$ (the latter by far the highest gradient we have ever recorded in a case of transposition). Failure to enter the pulmonary artery in complete (D-) transposition seems to have been entirely related to technique - thus all 5 failures occurred in the first 9 cases studied; subsequently we adopted the additional technique of moulding a distal curve on the catheter, and the pulmonary artery was successfully catheterized in all of the succeeding 14 patients. 


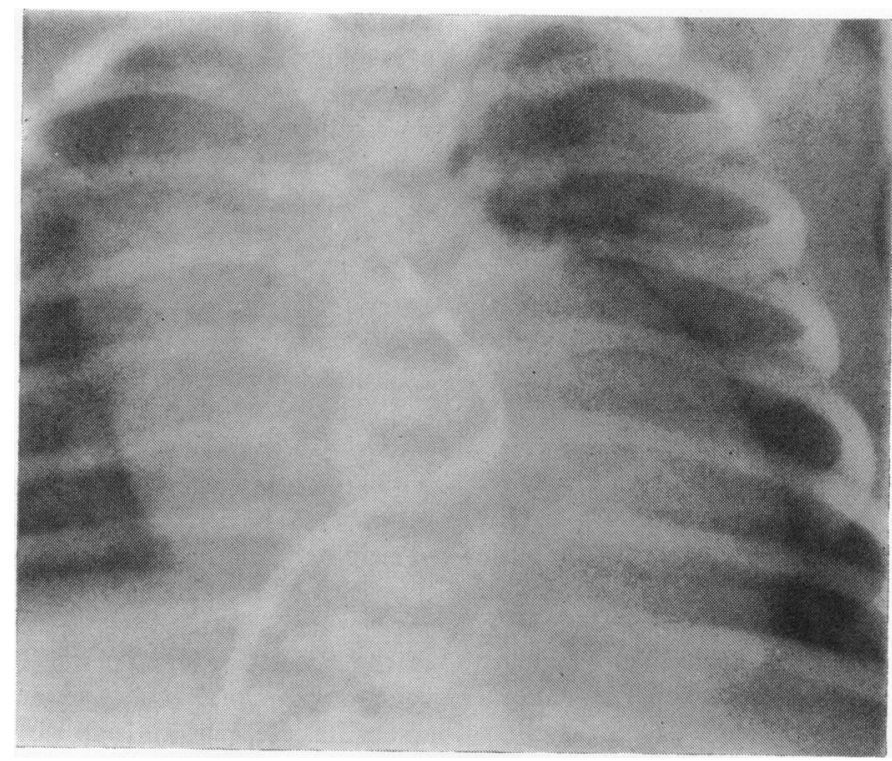

FIG. I Position of Swan-Ganz catheter in the main pulmonary artery via the left atrium and ventricle. It is an 'unlikely position of entry for a conventional semigrid catheter' (Kelly, Krovetz, and Rowe, 1971).

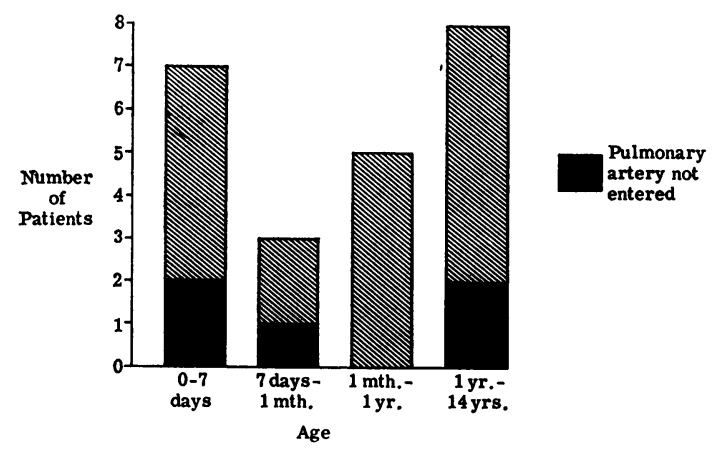

FIG. 2 Age distribution of patients and failure rate.

\section{Complex transposition}

There were 12 patients (age I month to 13 years) with some form of transposition of the great arteries other than D-transposition in situs solitus. Of these, 3 had L-transposition and a ventricular septal defect, 2 had L-transposition and double outlet right ventricle, and one L-transposition and double outlet left ventricle. Of 2 other patients with L-transposition, one had isolated laevocardia and a common ventricle and the other dextrocardia and a ventricular septal defect. There were 3 patients with complex D-transposition of whom one had tricuspid atresia, one a common ventricle, and one dextro- cardia. Finally, one patient had a double outlet right ventricle.

In this group of 12 patients, entry to the pulmonary artery was only achieved in $5(4 \mathrm{r} \cdot 5 \%)$; the average time taken was 5.6 minutes. Of the 8 with Ltransposition, the pulmonary artery was entered in only $3(37.5 \%)$. Three of the patients in whom the pulmonary artery was entered had mild-to-moderate pulmonary stenosis (gradients 30,40 , and $70 \mathrm{mmHg}$, respectively); on the other hand, 2 patients in whom the pulmonary artery could not be entered were subsequently shown (Radner suprasternal puncture) to have severe pulmonary stenosis (gradients 92 and $120 \mathrm{mmHg}$ ).

\section{Discussion}

In transposition of the great arteries entry into the pulmonary artery by conventional catheterization techniques is only attained in a minority of cases 20 per cent in the experience of Rahimtoola, Ongley, and Swan (1966). As a result, several special techniques have been employed, such as the use of a fine coaxial flow-guided catheter (Carr and Wells, 1966), percutaneous suprasternal puncture (Rahimtoola et al., 1966), and the use of a 'floppy' guide wire (Celermajer, Venables, and Bowdler, 1970) or catheter tip deflector (M. J. Tynan, 1972, personal communication) to direct the catheter towards the outflow region of the left ventricle. While consider- 
able success has accompanied these techniques in the hands of their originators, others have found them less useful. The coaxial flow-guided technique of Carr and Wells (1966) poses some technical problems and may be less useful in the presence of pulmonary stenosis. Suprasternal puncture (Rahimtoola et al., 1966) requires general anaesthesia and is certainly not without risk.

In 1970, Swan and associates predicted that their balloon-tipped flow-directed catheter might prove useful in the catheterization of complex cardiac malformations. This was confirmed by Kelly et al. in 1971, who employed the Swan-Ganz catheter in some 40 patients including 3 with transposition aged I year, 18 months, and 2 years. Our results confirm that this catheter provides a simple method of catheterizing the pulmonary artery in complete transposition - with slight modification of the catheter, our success rate has been IoO per cent. There have been no complications and general anaesthesia is not required. In many instances entry to the pulmonary artery from the left atrium has been so rapid that the continuously recorded pressure showed no evidence of passage through the left ventricle. The catheter has a relatively large lumen, and pressure recording and sampling pose no problems. Neither pulmonary stenosis nor small size of the patient appear to pose difficulties. Thus, 8 of the patients in whom the pulmonary artery was entered weighed less than $4 \mathrm{~kg}$; despite this, we have not felt the need for the smaller catheter and balloon proposed by Swan and associates (1970).

Although Swan and associates anticipated that their catheter would facilitate catheterization of 'corrected' transposition, our experience has been that this is an unfavourable situation. In complete transposition pulmonary flow is usually high, even in the presence of pulmonary stenosis - thus once the balloon has entered the left ventricle it tends to get carried to the pulmonary artery; indeed with an intact ventricular septum there is no other exit. This is not the situation in cases of 'corrected' trans- position with ventricular septal defect and pulmonary stenosis or cases of double outlet right ventricle with pulmonary stenosis. In such cases not only may pulmonary flow be less than systemic, but the balloon has an alternative 'exit' - into aorta. This may explain our higher incidence of failure in such cases.

In all our cases of complete (D-) transposition entry to the pulmonary artery was achieved via the left atrium and ventricle - thus success demands an interatrial communication, either a patent foramen ovale or atrial septal defect. Most neonates with transposition have some interatrial communication, while in older children an interatrial communication has usually been created as part of a palliative procedure. Alternatively, entry to the pulmonary artery may be achieved from the right ventricle via a ventricular septal defect - and we have had experience of the Swan-Ganz catheter being carried across a ventricular septal defect to a posterior pulmonary artery in cases with a high pulmonary flow.

\section{References}

Carr, I., and Wells, B. (1966). Coaxial flow-guided catheterisation of the pulmonary artery in transposition of the great arteries. Lancet, 2, 318.

Celermajer, J. M., Venables, A. W., and Bowdler, J. D. (1970). Catheterization of the pulmonary artery in transposition of the great arteries. Circulation, 41, 1053.

Kelly, D. T., Krovetz, L. J., and Rowe, R. D. (197I). Doublelumen flotation catheter for use in complex congenital cardiac anomalies. Circulation, 44, 9 ro.

Rahimtoola, S. H., Ongley, P. A., and Swan, H. J. C. (1966). Percutaneous suprasternal puncture (Radner technique) of the pulmonary artery in transposition of the great vessels. Circulation, 33, 242.

Swan, H. J. C., Ganz, W., Forrester, J., Marcus, H., Diamond, G., and Chonette, D. (1970). Catheterization of the heart in man with use of a flow-directed balloon-tipped catheter. New England fournal of Medicine, 283, 447.

Requests for reprints to Dr. G. A. H. Miller, Brompton Hospital, London $\mathrm{SW}_{3} 6 \mathrm{HP}$. 